\title{
Laparoscopic appendectomy in a second trimester pregnant patient due to acute appendicitis: a case report
}

\author{
Gamaliel Vázquez Estudillo ${ }^{1 *}$, Edwin Y. Ochoa Viveros ${ }^{1}$, \\ Rodrigo Nuñez Vidales ${ }^{2}$, Ivanhoe Larracilla Salazar ${ }^{2}$
}

\author{
${ }^{1}$ Department of General Surgery, Postgraduate School in Naval Health, Mexico City, Mexico \\ ${ }^{2}$ General Surgery Service of the General Hospital Naval of High Specialty (HOSGENAES), Mexico City, Mexico
}

Received: 28 March 2018

Accepted: 26 June 2018

\section{*Correspondence: \\ Dr. Gamaliel Vázquez Estudillo, E-mail:dr.gama.mcn@gmail.com}

Copyright: () the author(s), publisher and licensee Medip Academy. This is an open-access article distributed under the terms of the Creative Commons Attribution Non-Commercial License, which permits unrestricted non-commercial use, distribution, and reproduction in any medium, provided the original work is properly cited.

\begin{abstract}
Acute appendicitis is the most frequent surgical procedure of general surgery during pregnancy, which occurs in 0.04 to $0.2 \%$ of all pregnancies; this represents $25 \%$ of non-obstetric operations performed during pregnancy. A 33 -yearold female patient with a second-trimester pregnancy, which goes to the Emergency Department for abdominal pain, when performing the anamnesis and physical examination, the suggestive picture of acute appendicitis is integrated, for which additional laboratory and cabinet studies are carried out, according to the clinical suspicion it is decided to perform diagnostic laparoscopy and management according to findings; cecal erythematosus appendix is evident, so appendectomy is performed, finding proximal appendicolitis. Later with good evolution and satisfactory exit for the binomial. This procedure has been associated with shorter surgery times, shorter hospital stays and fewer complications compared to open surgery.
\end{abstract}

Keywords: Abdominal pain, Acute appendicitis in pregnancy, Laparoscopic appendectomy

\section{INTRODUCTION}

The incidence of acute abdomen occurs in up to 1 in 500 pregnancies, of the total cases reported, acute appendicitis is the surgical pathology of general surgery more frequent during pregnancy, which occurs in 0.04 to $0.2 \%$ of all pregnancies; this represents $25 \%$ of nonobstetric operations performed during pregnancy. ${ }^{1}$ Acute appendicitis was formally described in 1886 by Fitz, however 1848 Hancock mentions it as a complication in pregnancy. ${ }^{2}$ The incidence of appendicitis is slightly higher during the second trimester. In addition, a cohort study of more than 350,000 pregnancies reported that the rate of acute appendicitis was $35 \%$ lower during the predelivery period than the time outside of pregnancy. ${ }^{3}$

Despite the improvement in maternal mortality rates, peritonitis and resulting complications remain high in pregnancy, as well as the amount of white or negative appendectomy, which is greater than in the general population of up to 5 to $50 \% .^{3}$ Although, antibiotics and advances in imaging studies and effective surgical techniques have contributed to better results, this can be further improved if the threshold to operate on pregnant women with suspected symptoms is reduced. That is to say, the diagnostic suspicion continues to be clinical. ${ }^{4}$

The clinical manifestations of appendicitis in pregnancy are similar to those of non-pregnant persons; generally, in the first two trimesters of pregnancy the symptoms differ little from those presented by the non-pregnant woman. ${ }^{5}$

The clinical manifestations are the following

- Acute abdominal pain, usually beginning in the epigastrium or periumbilical region, which is then 
located in the right iliac fossa or slightly outward and upward.

- Vomiting (it has more value after the $1^{\text {st }}$ trimester since in the first trimester it can be confused with a (HG) Hiperemesis Gravidarum).

- Fever.

- Constipation although diarrhea may appear.

\section{Diagnostic laboratory and cabinet studies}

In women with abdominal pain, blood count with leukocyte count> $18,000 / \mathrm{dl}$ and deviation to the left is an element in favor of the diagnosis of appendicitis. Ultrasound (US) during pregnancy is safe and useful for identifying the etiology of acute abdominal pain and is the first-line imaging technique for abdominal pain during pregnancy. However, it is often inconclusive due to lack of visualization of the appendix due to the gravid uterus. $^{6}$ In case the ultrasound was not conclusive and depending on the availability of resources, the study of greater safety for the patient, with greater sensitivity and specificity is magnetic resonance imaging (MRI), as long as this diagnostic support is available; MRI has been considered as a study of choice if acute appendicitis is suspected in pregnancy; In case of not having MRI, the computed tomography (CT) is a diagnostic tool with high sensitivity and specificity. ${ }^{7}$

\section{CASE REPORT}

A 33-year-old female patient who attended the emergency service of the General Hospital Naval of High Specialty due to abdominal pain, was assessed by the Gynecology and Obstetrics Service, who requested assessment to the General Surgery Service for nonspecific abdominal pain.

Important antecedents: chronic-degenerative denied, allergies denied and surgical: Uterine Instrumented Curettage (UIC) 7 years ago and Manual Vacuum Aspiration (MVA) 1 year ago both due to abortion in the first trimester, currently with pregnancy of 23.2 weeks of gestation by date of last menstruation. Starts in the morning with abdominal pain in right iliac fossa, intensity 7/10 sharp type, accompanied by, anorexia, nausea and vomiting of gastro-bile content in 2 occasions so it is self-medical with butylhioscine $10 \mathrm{mg}$ orally with partial improvement, however, it exacerbates symptoms, denies transvaginal losses or fever and perceives fetal movements.

\section{Physical exploration}

Vital signs: TA $120 / 70 \mathrm{~mm} \mathrm{Hg}$, heart rate: 78 beats per minute, 19 breaths per minute, temperature $36.1^{\circ} \mathrm{C}$, conscious, oriented, cooperative, skin pallor, regular water status, algic facies, neurologically integrated, craniofacial without alterations, cylindrical neck without adenomegalies, thorax with adequate ventilatory mechanics clean pulmonary fields on auscultation, rhythmic cardiac area without aggregates. Globular abdomen at the expense of a pregnant uterus, with a single live product, a $20 \mathrm{~cm}$ uterus fundus, a cardiac focus of 145 beats per minute, without uterine activity, diminished peristalsis, tympanic, pain on superficial, middle and deep palpation in the right iliac fossa, with data of peritoneal irritation, positive appendiceal signs (Mc Burney, Rovsing, Capurro, Psoas, Talo percutor, maneuver of the obturator) Negative Murphy, vaginal touch with closed posterior cervix, formed, at the exit of the scout glove with non-fetid leucorrhoea, extremities without distal neurovascular alterations.

Laboratory studies are carried out, which reports blood count with leukocytes of 11,500 per cubic millimeter of blood and neutrophils of $76.3 \%$. Abdominal ultrasound reported, unique intrauterine live product of 24.2 weeks of gestation by photometry on average and an estimated weight of 698 gr., placenta subcenturiata, degree I of maturation in the Granum scale, amniotic fluid of echographic characteristics within the usual. Abdomen with finding of tubular image towards right iliac no compressible fossa. In relation to the anamnesis and physical examination, the suspected diagnosis of probable acute appendicitis is integrated (Alvarado 5 points), so the patient is explained the need to perform diagnostic laparoscopy and management according to findings. (Figure 1)

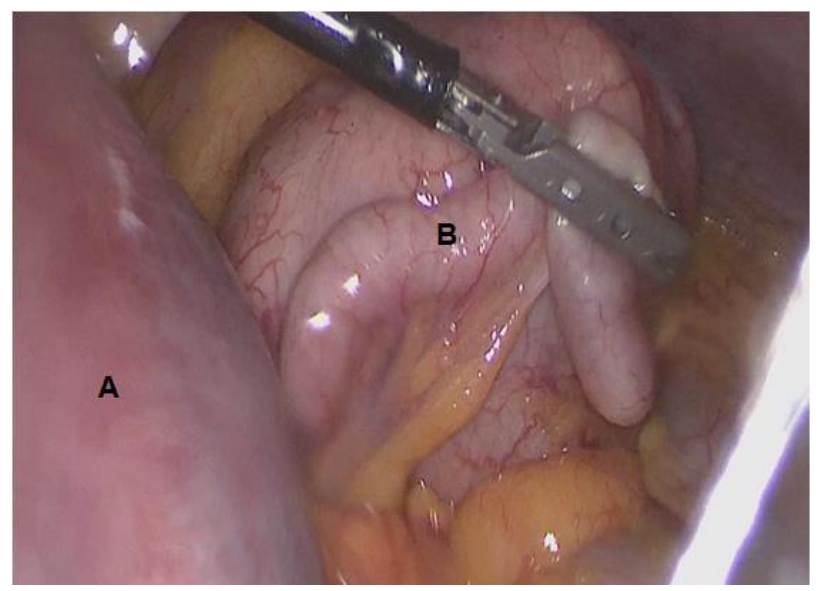

Figure 1: Cecal appendix, erythematous seen by laparoscopy. (A) Uterus. (B) Cecal appendix.

After balanced general anesthesia, asepsis and antisepsis was performed, cavity was approached with Veress technique, trocar was placed for $10 \mathrm{~mm}$ supra umbilical chamber, laparoscopy was performed and localized congestive cecal appendix, proceeded to placement of 10 $\mathrm{mm}$ trocar in fossa right iliac flanking gravid uterus and 5 $\mathrm{mm}$ trocar on the right flank, then dissected and resected mesoappendix with $5 \mathrm{~mm}$ laparoscopic Enseal clamp; once dissected mesoapendice; The cecal appendix was ligated proximally and distally by laparoscopic endoloop, appendicectomy was performed properly between the two ligatures using laparoscopic scissors, the cecal appendix was extracted with extractor bag, and the operation was 
concluded in a time of 25 minutes, after which the patient passed to recovery and floor of General Surgery with joint management and monitoring by Gynecology and Obstetrics.

\section{Surgical findings}

Pregnant uterus and inflammatory reaction fluid approximately $30 \mathrm{ml}$ in right iliac fossa. Cecal appendix in subcecal position of approximately $10 \times 1 \mathrm{~cm}$, edematous, erythematous base conserved, when appendectomy is performed appendicolito proximal (Figure 2).

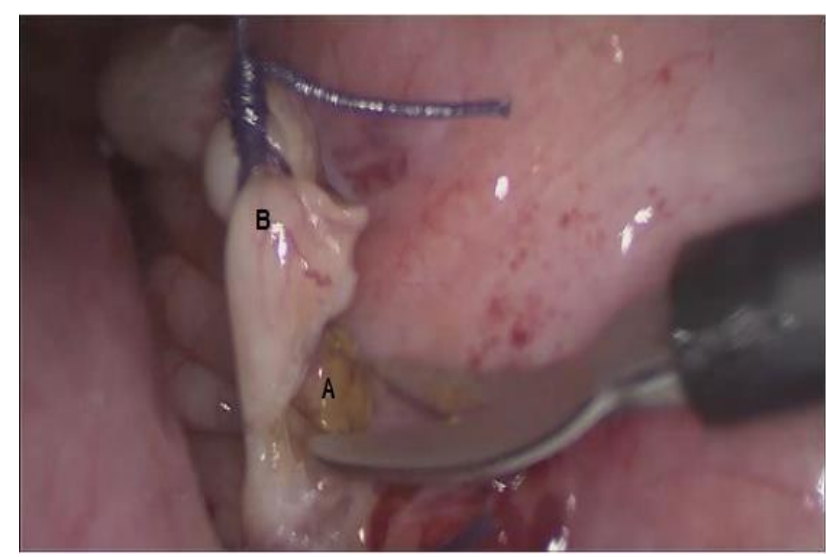

Figure 2: Appendectomy, proximal appendicolith is observed. (A) Appendicolite. (B) Cecal appendix.

\section{Evolution}

With 12 hours after the surgical event, the oral route was started, with adequate tolerance, good postoperative evolution and high 36 hours after laparoscopic appendectomy; previous assessment and confirmation of stability of the binomial in follow-up studies by the gynecology and obstetrics service, the patient was subsequently followed up by the external consultation. Pathology Report: Activation and hyperplasia of lymphoid tissue associated with mucous membranes.

\section{DISCUSSION}

The treatment of acute appendicitis is appendectomy. When the diagnosis is relatively safe, open appendectomy as laparoscopic are indicated and the choice will depend on the surgeon. When performing an open appendectomy in a pregnant woman, a transverse incision is made at the Mc Burney point or, more commonly, at the point of maximum pain, in case the diagnosis is less certain, the infraumbilical longitudinal incision is suggested. ${ }^{8}$ Laparoscopic appendectomy can be performed successfully during all trimesters and with few complications. ${ }^{9}$

In comparison with the national literature, in this clinical case, the patient was in the second period of pregnancy, which differs from that reported by Flores-Ramírez and Bolívar-Rodríguez, who report the first period, as the one with the highest incidence, likewise, the patient's age is within the group with the highest presentation, as reported by Basurto-Kuba. ${ }^{10-12}$

\section{CONCLUSION}

The clinical suspicion of acute appendicitis in pregnant patients with abdominal pain is very important, since the presentation of this pathology varies in each trimester; as well as the laboratory and cabinet studies, since they may not provide suggestive data initially. Laparoscopic treatment has been associated with shorter surgery times, shorter hospital stays and fewer complications compared to open surgery.

\section{Funding: No funding sources Conflict of interest: None declared \\ Ethical approval: The study was approved by the Institutional Ethics Committee}

\section{REFERENCES}

1. Cox TC, Huntington CR, Blair LJ, Prasad T, Lincourt AE, Augenstein VA, Heniford BT. Laparoscopic appendectomy and cholecystectomy versus open: a study in 1999 pregnant patients. Surgical Endos. 2016;30(2):593-602.

2. Donato Depalma. Historia de la cirugía infantil: Apendicitis. Rev Hosp Niños BAires. 2012; 54(244):15- 24.

3. Zingone F, Sultan AA, Humes DJ, West J. Risk of acute appendicitis in and around pregnancy: a population-based cohort study from England. Annals Surg. 2015;261(2):332-7.

4. Abbasi N, Patenaude V, Abenhaim HA. Management and outcomes of acute appendicitis in pregnancy-population-based study of over 7000 cases. BJOG: An Int J Obstet and Gynaecol. 2014;121(12):1509-14.

5. Wilson Laffita Labañino, William Jiménez Reyes. Acute appendicitis during pregnancy. Cuban J Obstet and Gynecol. 2011; 37(2):223-34.

6. Guterman S, Mandelbrot L, Keita H, Bretagnol F, Calabrese D, Msika S. Laparoscopy in the second and third trimesters of pregnancy for abdominal surgical emergencies. J Gynecol Obstet Human Reprod. 2017;46(5):417-2.

7. Burke LM, Bashir MR, Miller FH, Siegelman ES, Brown M, Alobaidy $\mathrm{M}$, et al. Magnetic resonance imaging of acute appendicitis in pregnancy: a 5-year multiinstitutional study. American J Obstet Gynecol. 2015;213(5):693-e1.

8. Andrei Rebarber, Brian P Jacob. Acute appendicitis in pregnancy. In: UpToDate, Charles J Lockwood, MHCM, Deborah Levin, Martin Weiser, UpToDate, Waltham, MA, 2018.

9. Michael P Stany, John C Elkas, JD. Laparoscopic surgery in pregnancy. In: UpToDate, Vincenzo 
Berghella, David L Hepner, Tommaso Falcone, FRCSC, FACOG, UpToDate, Waltham, MA, 2018.

10. Flores-Ramírez S, Flores-Morales JL, Fuentes-Rivas A. Appendicitis during pregnancy. Experience at the Hospital General Toluca Dr. Nicolás San Juan. Cirujano general. 2011;33(4):218-21.

11. Bolívar-Rodríguez MA, Cazarez-Aguilar MA, Fierro-López R, Romero-Aguilar RE, LizárragaGonzález H, Morgan-Ortiz F. Acute appendicitis during pregnancy: report of 4 cases. Ginecol Obstet Mex. 2014;82:337-43.
12. Basurto-Kuba EOP, Martínez- Gudiño O, OlmosRamírez G, Buitrón García-Figueroa R. Apendicitis y embarazo. Experiencia en el Hospital Ángeles México. Cirujano General 2006;28(4):230-3.

Cite this article as: Estudillo GV, Viveros EYO, Vidales NR, Salazar IL. Laparoscopic appendectomy in a second trimester pregnant patient due to acute appendicitis: a case report. Int J Reprod Contracept Obstet Gynecol 2018;7:3373-6. 